\title{
Distance discrimination in a simulated space environment'
}

\author{
ROBERT J. VINCENT, ${ }^{2}$ BILL R. BROWN, ROBERT P. MARKLEY, AND MALCOLM D. ARNOULT ${ }^{3}$ \\ TEXAS CHRISTIAN UNIVERSITY
}

The just noticeable difference (JND) for distance was investigated by a paired-comparisons method using successive comparisons. The research utilized an optically simulated large target located in a textureless environment at distances along the saggital plane out to $12,800 \mathrm{ft}$. The value of $\Delta D / D$ varied from less than $3 \%$ at $200 \mathrm{ft}$ to about $7 \%$ at 12,800 ft. The results confirmed a power function relationship between distance threshold and observation distance.

There have been several investigations of depth discrimination under experimental conditions in which judgments could be influenced both by binocular retinal disparity and by monocular cues to depth localization (Beebe-Center, Carmichael, \& Mead, 1944; Holway, Jameson, Zegler, Hurvich, Warren, \& Cook, 1945; Teichner, Kobrich, \& Dusek, 1955a; Teichner, Kobrick, \& Wehrkamp, 1955b; Jameson \& Hurvich, 1959). A summary by Teichner et al (1955a) concluded that the just perceptible difference in distance $(\Delta D)$ grows as the 1.35 power of observation distance,

$$
\Delta \mathrm{D}=.002 \mathrm{D}^{1.35}
$$

All of these studies shared several experimental characteristics which limited generalization of the results. Monocular cues are frequently peculiar to a particular stimulus situation. Even when a terrain effect was ruled out statistically (Teichner et al, $1955 \mathrm{~b}$ ) or, to some extent, experimentally (Beebe-Center et al, 1944), texture cues from the surround may nevertheless have been present. Moreover, the physical target sizes and the maximum viewing distances were typically small. The targets were usually rectangles with a maximum dimension of about $5 \mathrm{ft}$ and were located no more than and most often less than $300 \mathrm{ft}$ distant. Jameson and Hurvich (1959), citing results from the Holway et al (1945) paper, emphasized the importance of distance range by considering the curvature of the wave front of the light-bundle incident to the eye, since the curvature is related to changes in image clarity and ocular accommodation. Finally, the experiments discussed here were concerned only with the accuracy of equality settings. A literature search failed to locate a study which had established the proximal (approaching) and distal (receding) linear thresholds of distance.

This paper reports the results of a depth discrimination study which utilized an optically simulated large target (simulated size approximately $24 \mathrm{ft}$ high and $13 \mathrm{ft}$ in diam) located in a textureless environment at simulated distances along the saggital plane out to $12,800 \mathrm{ft}$. Unlike the previously cited studies, the standard and comparison targets were viewed sequentially rather than simultaneously.

\section{Subjects}

\section{METHOD}

Three male Os, ranging in age from 20 to 24 years, were paid to participate in this experiment. They were selected from a list of volunteers on the basis of possessing at least 20/20 visual acuity and high depth discrimination as judged by an optometrist.

\section{Apparatus}

Judgments were made of targets produced by an optomechanical simulator offering a high-fidelity, three- dimensional presentation of a $30 \times 13 \mathrm{ft}$ space vehicle (Apollo Command and Service Module) illuminated by a "sun" source in a start-free, outer-space environment. The light source was maintained at a constant distance from the target. Apparent brightness was thus appropriate with respect to the apparent distance. A special feature of the apparatus is that the simulated distance was achieved by having the apparent source of the light rays appropriate to the distance being presented. Thus, all the visual target cues which would be present in the real situation were provided in the simulation. The distance range available was $200 \mathrm{ft}$ to $20,000 \mathrm{ft}$. During all sessions, the target was tilted $37 \mathrm{deg}$ toward the $\mathrm{O}$, so that the maximum simulated vertical dimension was approximately $24 \mathrm{ft}$.

\section{Procedure}

Each $\mathrm{O}$ observed the target from a station in a room adjoining the simulator. He was seated in a fully-enclosed "capsule" and viewed the display through a 9-in. diam "porthole" situated $18 \mathrm{in}$. in front of him. His head was enclosed in a soft helmet which located his eyes in the optical axis. An intercommunication system provided verbal contact between the $E$ and $O$. Between the "porthole" and the final ocular lens there was a remotely controlled shutter used to occlude the scene between stimulus presentations.

The Method of Constant Stimuli was employed to establish the proximal and distal JNDs of distance for each of seven Standard Distances ranging in a geometric series from $200 \mathrm{ft}$ to $12,800 \mathrm{ft}$. It should be understood that the term "distance," in the context of the present experiment, refers to "apparent" distance in deference to the fact that the visual display was simulated.

Seven Comparison Distances for each Standard were selected during an extensive series of exploratory trials employing two Os. The criterion for selecting the range of Comparison Distances was that the most extreme proximal and distal distances should be judged correctly in at least 18 of 20 trials. The remaining Comparison Distances consisted of equally spaced (or occasionally equal logarithmically spaced) distances within this range. One of the Comparison Distances was identical to the Standard Distance. Once the Comparison Distances were selected, they were used for all Os. The data gathered in the exploratory trials were not included in the final analysis.

The procedure was the same for both the exploratory and final sessions. On a given day, each $\mathrm{O}$ made judgments at only a single Standard Distance, and each $O$ judged a different Standard that day. The Standard was presented first, and was identified by the $\mathrm{E}$ each time it appeared. Following a 3-sec exposure, the shutter occluded the scene; the target was then moved to a randomly selected Comparison Distance and $3 \mathrm{sec}$ later the shutter opened for $3 \mathrm{sec}$. The $O$ then responded "nearer" or "farther." No "equal" judgments were permitted. Following a 3-sec intertrial interval, this sequence was repeated until each Standard-Comparison pair had been presented 10 times. The Os judged each of the various Standards in a random fashion on three different days, making a total of 30 responses to each stimulus pair. The Os were not told the simulated distances of the Standard or Comparison stimuli until the termination of the experiment. 


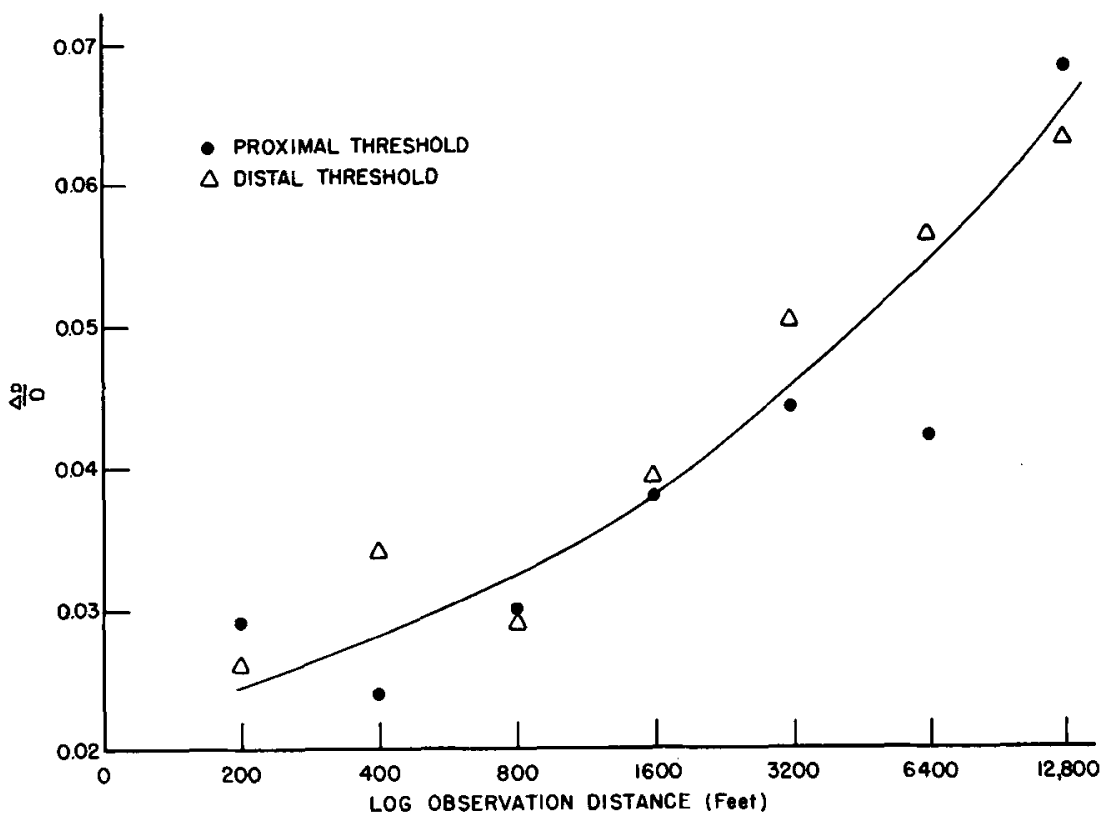

Fig. 1. Proximal and distal differential distance discrimination as a function of observation distance. The curve was fitted by eye with no distinction made between proximal and distal thresholds.

\section{RESULTS}

The percentage of "nearer" responses for all Os to each Standard-Comparison pair were treated as ordinate values on a normal distribution and were converted to standard scores. The standard scores were plotted against the Comparison stimuli. The interpolated Comparison Distance corresponding to -1 SD (standard deviation) defined the proximal threshold $(\Delta D)$; that for the $+1 \mathrm{SD}$ defined the distal threshold. The procedure follows that discussed by Woodworth and Schlosberg (1954). that

An initial analysis was made to test if Weber's law held, such

$$
\Delta \mathrm{D}=\mathrm{KD}^{1.0} .
$$

Figure 1 depicts the results of plotting $\Delta D / D$ against $\log D$. The curve was fitted to the data by eye with no distinction made between proximal and distal thresholds. It is clear that the strict Weber relation was not found, nor was there support for the generalized Weber function endorsed by Ogle (1952)

$$
\Delta \mathrm{D}=\mathrm{K}(\mathrm{D}+\Delta \mathrm{D})^{1.0}
$$

The analysis is not shown here, but the values of $\Delta D /(D+\Delta D)$ ranged from 0.03 at $200 \mathrm{ft}$ to 0.07 at $12,800 \mathrm{ft}$, and were very nearly the same for both the proximal and distal thresholds. In other words, rather than being a constant proportion of observation distance, $\Delta \mathrm{D} / \mathrm{D}$ and $\Delta \mathrm{D} /(\mathrm{D}+\Delta \mathrm{D})$ increase progressively with observation distance.

Inspection of Fig. 2 reveals that the JND for distance increases exponentially with distance and with visual angle $(\alpha)$. The proximal and distal thresholds are plotted separately. Each point was based upon 90 responses. The points were fitted by least squares. The resulting power functions were

$$
\begin{aligned}
\Delta D_{P} & =0.011 D^{1.19} \\
\Delta D_{d} & =0.011 D^{1.20},
\end{aligned}
$$

where $\Delta D_{\mathrm{P}}$ and $\Delta D_{\mathrm{d}}$ designate the proximal and distal thresholds, respectively. There appeared to be no consistent differences in the magnitude of the corresponding thresholds.

In terms of angular subtense of the vertical dimension of the target, the least perceptible difference in retinal size of the stimulus is shown to grow as a power function of target size,

$$
\begin{aligned}
& \Delta \alpha_{\mathrm{p}}=0.108 \alpha^{0.78} \\
& \Delta \alpha_{\mathrm{d}}=0.112 \alpha^{0.79}
\end{aligned}
$$

Teichner et al (1955a) averaged the data from several studies concerned with depth discrimination at various observation distances and concluded that $\triangle D$ grows approximately as the 1.35 power of $\mathrm{D}(\mathrm{Eq} .1)$. Their results are reported in Fig. 3 (adapted from Teichner's Fig. 1, 1955a). The lowest curve was fitted to the data by Eq. 1 .

Superimposed on Teichner's results are the findings from the present study (half-filled circles). Despite the differences in absolute values of the threshold, the general agreement between the present results and those reported by Teichner et al (1955a) is impressive, considering the many differences in the experimental situations.

Assuming adequacy of the distance simulation, the practical meaning of these results is as follows: (a) At a distance of $200 \mathrm{ft}$ an $\mathrm{O}$ should be able to detect reliably a change in distance of only $5 \mathrm{ft}$, even under conditions of successive observation; at a range of $12,800 \mathrm{ft}$, the minimum detectable change is of the order of $800 \mathrm{ft}$; (b) in terms of size change of a large target (maximum dimension $=27.34 \mathrm{ft}$ ), at $200 \mathrm{ft}$ a size change of $11 \mathrm{~min} 16 \mathrm{sec}$ of visual arc could be detected (target size $=408 \mathrm{~min}$ of visual arc); at $12,800 \mathrm{ft}$ a size change of $26 \mathrm{sec}$ of arc could be detected (target size $=6 \mathrm{~min} 22 \mathrm{sec}$ of visual arc). It should be noted again that these discriminations were made under conditions such that almost all of the normal terrestrial cues to distance were missing.

\section{DISCUSSION}

In one respect, the results of the present investigation may be interpreted as a test of the adequacy of the simulation of distance. In view of the correspondence between the results reported here and those of previous studies there is no response-based reason for doubting the validity of the display.

The present study confirms the power function relationship between distance threshold and observation distance even under relatively restricted viewing conditions. Because of the particulars of the experimental design, however, unanswered questions remain concerning the relative importance to distance judgment of the several empirical factors listed by 


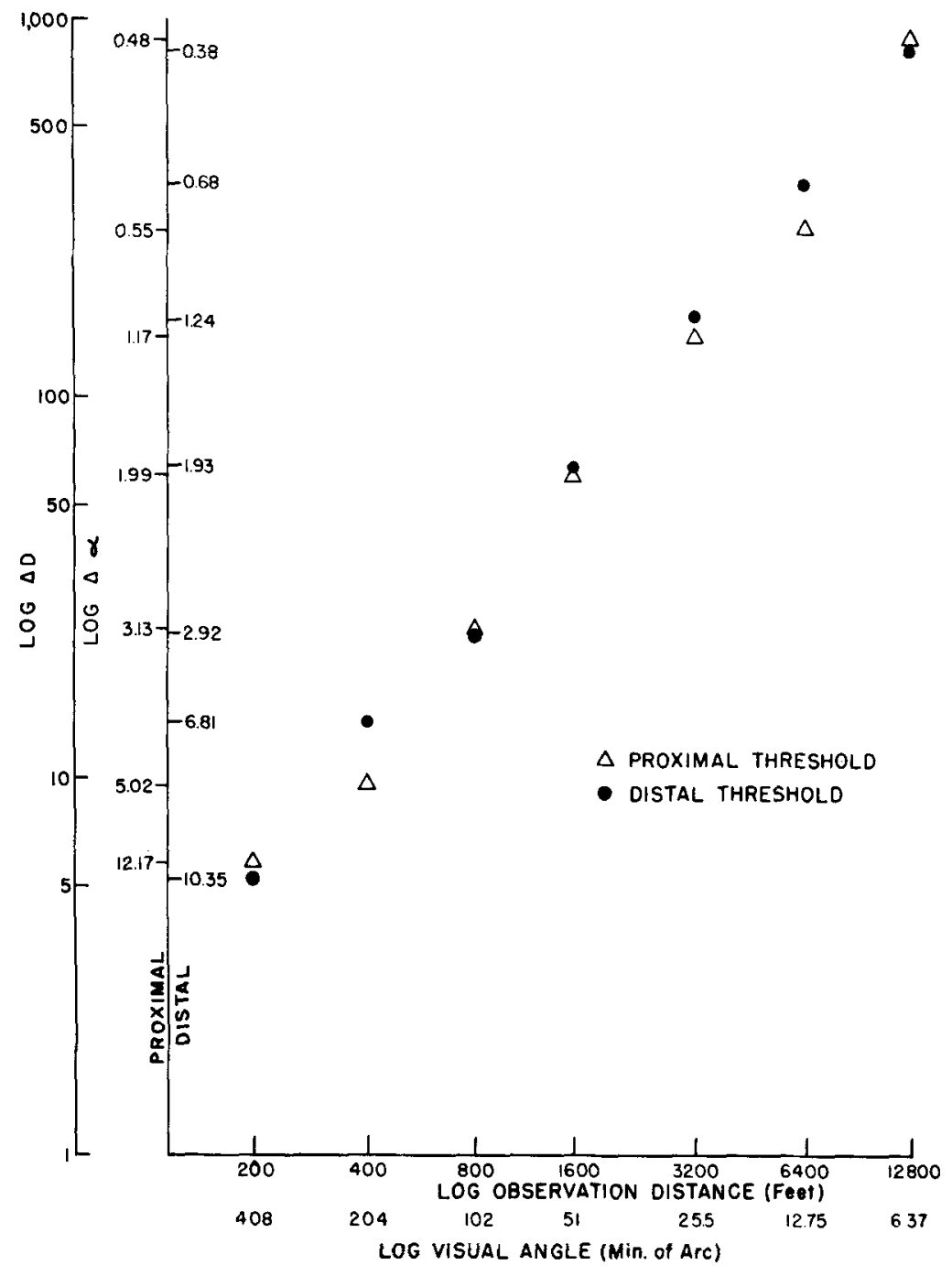

Fig. 2. Proximal and distal thresholds for distance and visual angle as a function of observation distance and visual angle.

Ogle $(1958,1962)$. The authors favor change in retinal image-size as the most significant cue to depth localization in the present experiment. This conclusion is similar to that of Holway et al (1945). There is also the possibility that changes in binocular disparity and the characteristics of the light-ray bundles were involved. In fact, Jameson and Hurvich (1959) reanalyzed specific aspects of the earlier Holway et al (1945) data and concluded that retinal image size, binocular disparity, and light-ray configurations work together in an additive fashion to produce depth discrimination.

It is doubtful that binocular disparity played a significant role in the present results. It seems unreasonable to assume that Os were making judgments on the basis of a change in binocular parallax angle when the targets were viewed sequentially with a $3 \mathrm{sec}$, interpresentation interval. Parenthetically, the mode of presentation tends to weaken the possibility that Os were relying upon vernier alignment of the Standard and Comparison targets, an explanation offered by Teichner et al $(1955 \mathrm{a}, \mathrm{b})$ with respect to the situation in which the targets are presented simultaneously. Cues from binocular disparity involve differences between the images in the two eyes. In the case of sequential presentation, then, the comparison would have to be between the binocular disparity present on one occasion with a trace of the disparity present in the images recorded $3 \mathrm{sec}$ earlier. Such a comparison is not impossible, but present knowledge of the visual system would render it highly unlikely.
By the same token, it should be noted that judgments based solely on size change likewise require a comparison of present stimulation with the trace of past stimulation. For this reason the threshold values obtained must be considered remarkably small.

One final possibility that might be considered is that judgments were based on a detection of change in convergence or accommodation from the first presentation to the second. While the shutter was closed, $O$ may have maintained visual fixation and may also have had an afterimage of the stimulus. Exposure of the second stimulus would then have produced small changes in convergence and accommodation. If an afterimage was present, a small amount of apparent movement of the target might have been detected as well. These possibilities could be investigated by providing a fixation point on the shutter. A change in fixation between presentations should have the effect of increasing the threshold values. Another method of checking the reliability of the results would be to replicate the experiment using a target of different size and shape. Such a replication is currently in progress.

\section{REFERENCES}

BEEBE-CENTER, J. G., CARMICHAEL, L., \& MEAD, L. C. Daylight training of pilots for night flying. Aeronautical Engineering Review, 1944, 3, 1-10.

HOLWAY, A. H., JAMESON, D. A., ZIGLER, M. J., HURVICH, L. M., WARREN, A. B., \& COOK, E. B. Factors influencing the magnitude of 


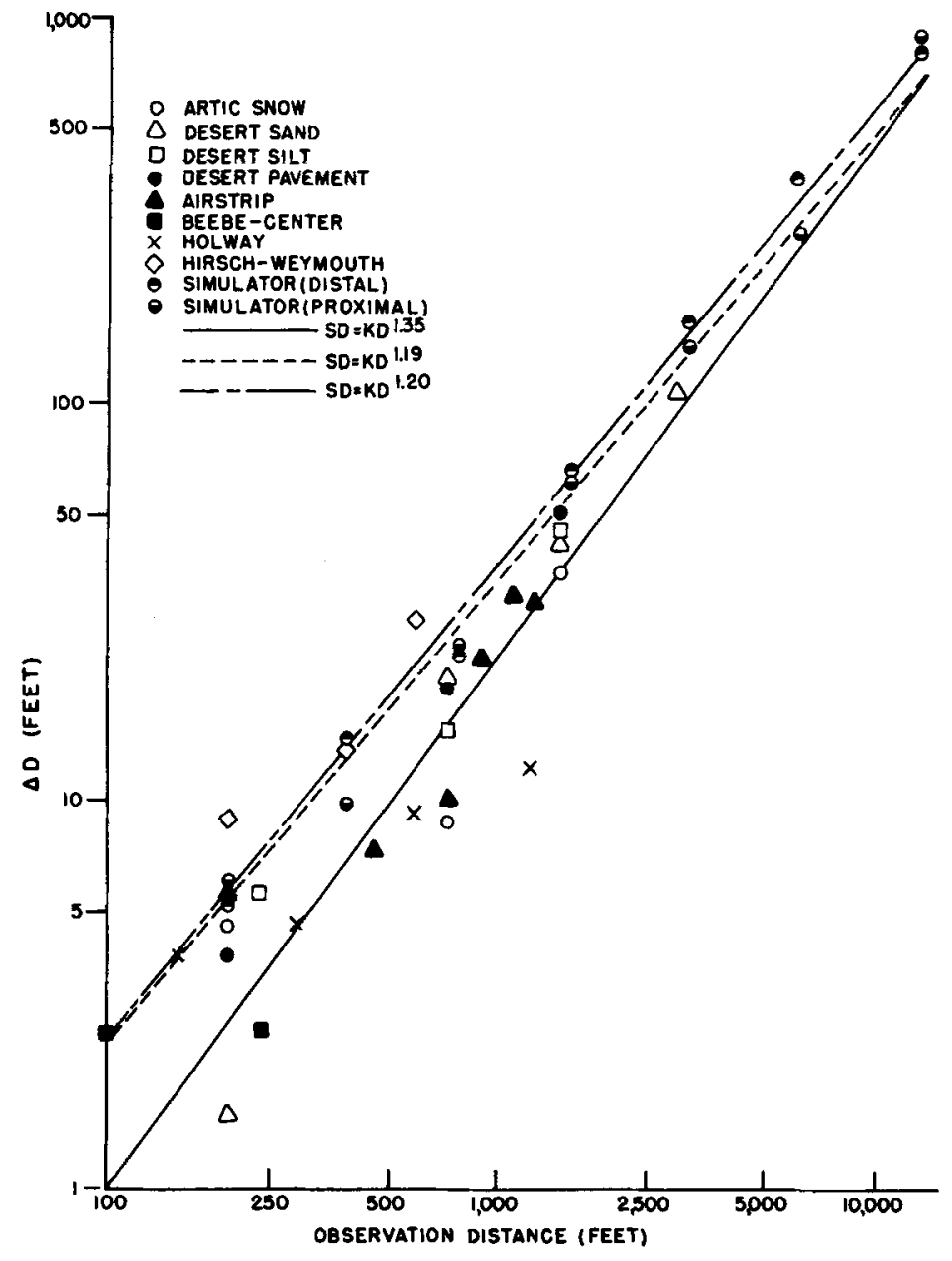

Fig. 3. Data from Fig. 1, Teichner et al (1955a) and present study (half-filled circles) showing distance discrimination as a function of observation distance. The lowest curve was fitted by the empirical formula $\Delta D=0.002 D^{1.35}$. The proximal curve was fitted by the empirical formula $\Delta \mathrm{D}=0.01 \mathrm{D}^{1.19}$; the distal curve by $\Delta \mathrm{D}=0.011 \mathrm{D}^{1.20}$.

range errors in free space and telescopic vision. Division of Research, Graduate School of Business Administration, Harvard University, 1945, 1-314.

JAMESON, D., \& HURVICH, L. M. Note on factors influencing the relation between stereoscopic acuity and observation distance. Journal of the Optical Society of America, 1959, 49, 639.

OGLE, K. N. Note on stereoscopic acuity and observation distance. Journal of the Optical Society of America, 1958, 48, 749-798.

OGLE, K. N. Perception of distance and size. In H. Davson (Ed.), The Eye, Vol. IV. New York: Academic Press, 1962.

TEICHNER, W, H., KOBRICK, J. L., \& DISEK, E. R. Commonplace viewing and depth discrimination. Joumal of the Optical Society of America, 1955a, 45, 913-920.

TEICHNER, W. H., KOBRICK, J. L., \& DISEK, E. R. The effects of terrain and observation distance on relative depth discrimination. American Journal of Psychology, 1955b, 68, 193-208.
WOODWORTH, R. S., \& SCHLOSBERG, H. Experimental psychology. New York: Holt, Rinehart, and Winston, 1954.

\section{NOTES}

1. This research and preparation of this paper was supported by Contract NAS 2-1481 and Grant NGR 44009018 from the National Aeronautics and Space Administration to Texas Christian University, M. D. Arnoult, Principal Investigator. Portions of this paper appeared as Document NASA CR 73 205, dated January, 1968.

2. Now residing in Waidorf, $\mathrm{Md}$

3. Address: Department of Psychology, Texas Christian University, Fort Worth, Texas 76129.

(Accepted for publication October 7, 1968.) 